\title{
e-Interview
}

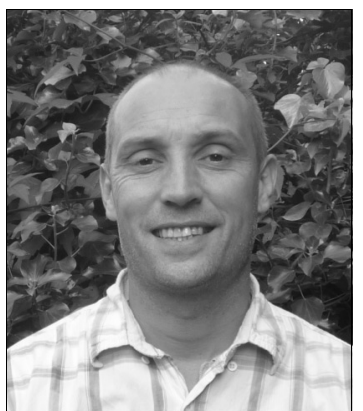

\section{Dr Rufus May}

Rufus May is a clinical psychologist with Bradford Early Intervention Service and Bradford's adult mental health services. He trained at the University of East London. His special interests include emancipatory approaches to hearing voices, unusual beliefs and complex trauma reactions.

If you were not a psychologist, what would you do?

I would be a martial arts teacher in the evening and run a community café in the day-time.

What has been the greatest impact of your work on you personally? Working with the Hearing Voices Network which has found a way to de-pathologise people's mental experiences and work collaboratively towards emancipation.

Do you feel stigmatised by your profession?

I think we should hold our profession lightly. First and foremost, we are members of various communities. There is a danger we become too attached to seeing ourselves in terms of our profession and this can be limiting.

\section{What are your interests outside} of work?

I use Zen meditation every day before work. As well as walking the dog, this helps me feel grounded and refreshed to focus on helping other people. The occasional retreat helps me replenish my energies.

\section{Why did you choose to train as a} psychologist?

When I had a breakdown at 18 I received very biological treatment for my confusion.
I felt that my mental health problems were a reasonable reaction to difficult life events. I sought alternative forms of help including drama, dance, art, leaving home and finding people who would accept me as I was but also ask me to contribute. I trained as a psychologist to promote the idea that all behavior and experiences are meaningful and we should be very creative in helping people reconnect with life when they are overcome with difficult thoughts and feelings.

Who was your most influential trainer and why?

Probably Mary Boyle because she taught me to question the way language is used to describe reality. There are always different ways of understanding people's lives that may open up fresh possibilities.

\section{What job gave you the most useful} training experience?

Working in Tower Hamlets with Brigid McCarthy and colleagues. I helped set up a group therapy project for people with psychosis in the 1990s. From this work, I was convinced of the power of groups to help people help themselves and each other.

Which publication has influenced you most?

I like Open Mind, Asylum magazine, and the journal Psychosis has some very good articles. The book Anger: Buddhist Wisdom for Cooling the Flames by Thich Nhat Hanh was extremely influential on all parts of my life.

What part of your work gives you the most satisfaction?

Witnessing people who have been misunderstood finding a voice.

\section{What do you least enjoy?}

Seeing how much money and time is put into controlling approaches instead of empowering approaches.

What is the most promising opportunity facing the mental health professions? Mindfulness offers mental health workers a good way to look after themselves and share skills with the people they work with. I would like to see more spaces for mindfulness in team meetings and the structure of services.
What conflict of interest do you encounter most often?

Professional self-interest seems to conflict with 'how would we or our relatives like to be treated?' This should be the question we should always be asking.

What is the role of the mental health professional in countries emerging from conflict?

As with all mental health work, it is about reconciliation with conflicting emotions and needs, being part of building healthier communities and contributing to restorative justice approaches.

What is the most important advice you could offer to a new trainee?

Read survivor stories and learn from the diversity of things that seem to have been helpful to them in rebuilding their lives. Attend events where people speak up about their experiences. Keep being creative and questioning.

\section{Do you think psychiatry is brainless} or mindless?

It is mindless if it blames the brain for people's difficulties.

What single change to mental health legislation would you like to see? We should get rid of the Law of Diminished Responsibility. All violence is not committed in people's right minds. Separating out 'mad crime' from 'sane crime' is unhelpful as it stigmatises the experience of madness and denies the fact that people have an ability to make ethical choices even under the influence of voice-hearing or delusions.

What single area of psychiatric practice is most in need of development? Listening skills.

How would you like to be remembered? For being part of a broad-scale movement to bring the heart back into approaches to helping people who are confused and distressed. Also, as someone who likes to dialogue with demons rather than trying to get rid of them.

Dominic Fannon

doi: $10.1192 / p b . b p .111 .038224$ 